\title{
Association Between Maternal Weight Gain in Different Periods of Pregnancy and the Risk of Venous Thromboembolism: A Retrospective Matched Case-Control Study
}

\section{Yuelin Wu}

Shanghai First Maternity and Infant Hospital, School of Medicine, Tongji University Jindan Pei

Shanghai First Maternity and Infant Hospital, School of Medicine, Tongji University Lingling Dong

Shanghai First Maternity and Infant Hospital, School of Medicine, Tongji University Zheying Zhou

Shanghai First Maternity and Infant Hospital, School of Medicine, Tongji University

Tianfan Zhou

Shanghai First Maternity and Infant Hospital, School of Medicine, Tongji University

Xiaobo Zhao

Shanghai First Maternity and Infant Hospital, School of Medicine, Tongji University

\section{Ronghua Che}

Shanghai First Maternity and Infant Hospital, School of Medicine, Tongji University

\section{Zhimin Han}

Shanghai First Maternity and Infant Hospital, School of Medicine, Tongji University

Xiaolin Hua ( $\nabla$ xiaolin_hua@tongji.edu.cn )

Shanghai First Maternity and Infant Hospital, School of Medicine, Tongji University

\section{Research Article}

Keywords: Venous thromboembolic disease, pulmonary embolus, gestational weight gain, pregnancy outcomes, z-scores

Posted Date: December 3rd, 2021

DOI: https://doi.org/10.21203/rs.3.rs-1133612/v1

License: (9) This work is licensed under a Creative Commons Attribution 4.0 International License. Read Full License 


\section{Abstract}

Background Although the rate of maternal mortality has declined over the past few decades, pulmonary embolus (PE) remains an important cause of maternal deaths. Little is known about the associations of specific periods of gestational weight gain with detailed PE and deep venous thrombosis (DVT). We explored the incidence of pregnancy-related venous thromboembolism (VTE) in China and assessed the associations of maternal weight gain in different periods of pregnancy with VTE.

Methods In a retrospective case-control study conducted in in Shanghai First Maternity and Infant Hospital from January $1^{\text {st }}, 2017$ to July $31^{\text {th }}, 2021,151$ cases $(11.7$ per 10000) of venous thromboembolism (VTE) within pregnancy or the first 6 postnatal weeks were identified. 302 controls without VTE who gave birth at the same time as the cases were selected. Maternal pre-pregnancy weight, weight in early, mid and late pregnancy and other maternal pregnancy and newborn characteristics were obtained. GWG was standardized into gestational age-specific z-scores stratified by body mass index $(\mathrm{BMI})$ and categorized as low (z score $<-1)$, normal $(-1$ to 1$)$, and high $(>1)$. The adjusted odds ratios (aORs) and 95\% confidence intervals (Cls) were estimated through log-binomial regression models. Interaction effects between gestational weight gain (GWG) and some other adjustment factors were tested, further stratified analyses were performed separately where interaction terms were significant.

Results There were $65.6 \%$ (99 of 151) of pulmonary embolus (PE) alone and 34.4\% (52 of 151) of deep venous thrombosis (DVT) alone or combined with PE. For all pre-pregnancy BMI categories (underweight, normal weight, overweight and obese), there was no statistical association between maternal weight gain of all gestational intervals and DVT or all VTE in this study. However, for PE, there was observed protective effects of low weight gain (aOR $0.79 ; 95 \% \mathrm{Cl} 0.37-1.68)$ and significantly increased risks of high weight gain (aOR=1.47; 95\% Cl: 1.03-2.09) among normal-weight women in early pregnancy. Similarly, a tendency towards decreased risk at lower weight gain throughout pregnancy (aOR 0.79; 95\% $\mathrm{Cl} 0.37-1.68)$ and significantly increased risk at higher values (aOR=1.52; 95\% $\mathrm{Cl}$ : 1.01-2.31) for PE was observed in normal-weight women. As for underweight and overweight women, results from the categorical model for early, late or total pregnancy weight gain indicated an increased risk in PE at both low and high weight gain, but confidence intervals were wide.

\section{Conclusion}

Chinese women have a higher risk of PE than the foreigner counterparts. Maternal weight gain in total or early pregnancy is an important risk factor for PE. In order to effectively improve maternal and child outcomes, intensive weight management that continues through pregnancy may be indispensable.

\section{Introduction}

Deep vein thrombosis (DVT) and pulmonary embolism (PE) are collectively referred to as venous thromboembolic disease (VTE). Although the rate of maternal mortality has declined over the past few decades, PE remains an important cause of maternal deaths ${ }^{[1,2]}$. During pregnancy, a women's risk of VTE 
is increased by 6 times, with reported incidence ranging from 0.5 to 2.0 per 1000 deliveries $^{[3,4]}$. Approximately $75-80 \%$ of cases of pregnancy-associated VTE are caused by DVT, and $20-25 \%$ of cases are caused by $\mathrm{P}{ }^{[5]}$. However, few studies have examined trends in the incidence of pregnancy-related VTE in China.

Several studies have already identified risk factors for pregnancy-related VTE, including advanced maternal age, greater body mass index (BMI), cesarean delivery, preeclampsia, postpartum hemorrhage and newborns with low birth weight ${ }^{[1,6-11]}$. They help care providers to target the use of thromboprophylaxis to women at risk to maximize its benefit ${ }^{[12]}$. However, few studies have evaluated gestational weight gain (GWG) as a risk factor for VTE ${ }^{[13]}$. Although insufficient and excessive maternal weight gain has been linked with increased risks of $\mathrm{VTE}^{[13]}$, they have often not accounted for the effects of weight gain during certain periods of pregnancy. Furthermore, the associations of specific periods of GWG with detailed PE and DVT has not been reported. In addition, few studies have examined trends in the incidence of pregnancy-related VTE in China, and these studies have shown variable results ${ }^{[14,15]}$.

For this retrospective case-control study of women, our objective was to explore the incidence of pregnancy-related VTE in China, and evaluate the association of maternal weight gain in different periods of pregnancy with detailed pulmonary embolism (PE) and deep vein thrombosis (DVT).

\section{Materials And Methods}

\section{Study design}

We performed a retrospective case-control study, using data on all prenatal visit and discharges from Shanghai First Maternity and Infant Hospital for the period of January $1^{\text {st }}, 2017$ to July $31^{\text {th }}, 2021$ to evaluate the effect of maternal weight gain in different periods of pregnancy on VTE at any site. Written informed consent was obtained from the participants. The data including maternal demographical characteristics, reproductive history, as well as clinical information related to this pregnancy were collected. This study was approved by Ethics Committee of Shanghai First Maternity and Infant Hospital (reference number: KS2057).

\section{Study population}

Women with a diagnosis of DVT or PE, which combined VTE in pregnancy or in the first 6 postnatal weeks were identified by search for selected ICD-9 or 10 codes in the Hospital Information System. 192 women were registered with a diagnosis of VTE in 129443 pregnancies. We excluded 3 cases wrongly diagnosed with VTE in index and subsequent pregnancies, 3 cases with thrombotic events in association with miscarriage, induced abortion, or ectopic pregnancy terminated before gestational week 28 . In addition, we excluded possible cases with a diagnosis of amniotic fluid embolism $(n=7)$. Further exclusions were applied to women who started antenatal care after 18 week's gestation $(n=2)$ and women with missing data for pre-pregnancy, delivery weight and height information $(n=26)$. Finally, we excluded 
3 cases with server heart/liver/kidney disease, malignancy or history of VTE. The eligible case population comprised 151 women (Figure 1).

The Hospital Information System selected first two women without VTE in pregnancy or the first 6 weeks following delivery, who gave birth at Shanghai First Maternity and Infant Hospital at the same time as the case, as possible controls. If these women did not meet the criterions above, we included the $3 \mathrm{rd}$ or 4 th selection as controls. In total 302 controls were identified.

\section{Weight measurements}

Gestational age was estimated based on the date of last menstruation period and confirmed by first trimester ultrasound date. Pre-pregnancy weight $(\mathrm{kg})$ was based on self-reporting, while weight at every prenatal visit and at delivery was routinely measured to the nearest $0.1 \mathrm{~kg}$ using the available electronic weighing device in the prenatal care clinics. Height $(\mathrm{cm})$ at the first prenatal visit was routinely measured to the nearest $0.1 \mathrm{~cm}$ using the available electronic stadiometer in the hospital. Pre-pregnancy body mass index $\left(\mathrm{BMl} ; \mathrm{kg} / \mathrm{m}^{2}\right)$ was calculated as pre-pregnancy weight $(\mathrm{kg})$ divided by height $(\mathrm{m})^{2}$ and categorized as underweight $\left(<18.5 \mathrm{~kg} / \mathrm{m}^{2}\right)$, normal weight (18.5 to $\left.24.9 \mathrm{~kg} / \mathrm{m}^{2}\right)$, overweight (25.0 to $29.9 \mathrm{~kg} / \mathrm{m}^{2}$ ), and obese $\left(\geq 30.0 \mathrm{~kg} / \mathrm{m}^{2}\right)^{[16]}$. However, due to the sporadic number of obese women, we analyze them together with overweight women in this study.

We defined the following 3 gestational intervals: $\leq 14,24$ to $28,>28$ weeks. If a woman had more than 1 antenatal visit within an interval, we took her last weight measurements for that interval. GWG in early pregnancy was calculated as the antenatal weight up to $\leq 14$ weeks minus the pre-pregnancy weight; GWG in mid pregnancy was calculated as the weight measured in 24 to 28 weeks' intervals minus the last weight measured $\leq 14$ week, and late pregnancy as last measurement of weight prior to delivery minus the weight measured in 24 to 28 weeks' intervals. Total GWG was calculated as last measurement of weight before delivery minus pre-pregnancy weight. All GWG values were standardized into z-scores by gestational age, stratified by BMI categories. The means and standard deviations (SD) of GWGs in early, mid, late and whole pregnancy were used to convert the GWG values into z-scores. All GWG z-scores were first examined as continuous variables, and then categorized as $<-1.0$ (below), -1.0 to +1.0 (average) and $>+1.0$ (above) in data analyses.

\section{Exposure and other variables}

Maternal demographics and lifestyle characteristics included maternal age ( $\geq 35$ years or no), parity ( 0 or no), education (university degree and above or no), ART (intrauterine insemination (IUI); IUI with ovulation induction but without in-vitro fertilization (IVF); IVF; IVF with intracytoplasmic sperm injection (ICSI); ovulation induction without IVF and vaginal insemination), pre-pregnancy body mass index (BMI) categories (underweight, normal, overweight/obese).

Maternal pregnancy characteristics and complications included gestational age at delivery, delivery mode (vaginal delivery, either spontaneous or by vacuum extraction or forceps, and cesarean section, either 
planned or by emergency), multiple pregnancy, gestational diabetes mellitus (GDM), pregnancy induced hypertension (PIH), hypothyroidism, preterm birth ( $<37$ week), postpartum hemorrhage $(>500 \mathrm{~mL}$ after vaginal delivery, blood loss $>1000 \mathrm{~mL}$ after cesarean delivery), premature rupture of membranes, ischemic placental diseases (composite of preeclampsia, intrauterine growth retardation (IUGR), placental abruption and stillbirth), placenta previa, abruptio placentae and postpartum transfusion.

Newborn characteristics included fetal sex, birthweight, small for gestational age (SGA) $\leq 10^{\text {th }}$, large for gestational age ( $L G A) \geq 90^{\text {th }}$ according to Chinese sex- and gestational age-specific birth weight standards ${ }^{[17]}$, macrosomia ( $\left.>4000 \mathrm{~g}\right)$, low birthweight $(<2500 \mathrm{~g})$, very low birthweight $(<2500 \mathrm{~g})$, sentinel congenital anomalies (atrial septal defect, ventricular septal defect, esophageal fistula, hypospadias), respiratory distress syndrome and hyperbilirubinemia (>12 $\mathrm{mg} / \mathrm{dL})$.

\section{Statistical analyses}

Maternal demographic characteristics and clinical factors were compared between venous thrombosis cases and control groups. Continuous variables were described by mean with standard deviation (SD) or median with interquartile range (IQR). Categorical variables were described by frequencies (\%). Analysis of variance or Kruskal-Wallis $\mathrm{H}$ tests were performed for continuous data, and chi-square tests or Fisher's exact tests were performed for categorical data.

Multivariate log-binomial regression models were used to estimate the adjusted odds ratios (aORs) and 95\% confidence intervals (Cls) for separately PE alone, DVT (including DVT and concomitant PE) and all VTE events across GWG in different periods of pregnancy. Regression model were adjusted for only covariables with $p<0.2$ (maternal age, parity, ART, delivery mode, fetal number, birthweight, PIH, GDM and postpartum hemorrhage). Interaction effects between GWG and other covariates (parity, birthweight, maternal age and delivery mode) on venous thrombosis were also tested.

All analyses were performed using the Statistical Analysis System (SAS) for Windows, version 9.4 (SAS Institute, Cary, NC). P<0.05 was considered statistically significant.

\section{Results}

\section{Study population and characteristics}

A total of 129443 women gave birth in Shanghai First Maternity and Infant Hospital between January $1^{\text {st }}$, 2017 and July $31^{\text {th }}, 2021$ and 151 (11.7 per 10000) women experienced VTE in pregnancy or in the first 6 postnatal weeks. Of these, $65.6 \%$ (99 of 151) was PE alone and $34.4 \%$ (52 of 151) was DVT alone or combined with PE. 302 women who did not experience a VTE were selected as control. The prevalence of known risk factors for VTE was significantly higher in cases than controls (Table 1). In particular, cases were more likely to be of advanced age (23.2\% versus $14.3 \%)$, to be overweight or obese $(19.3 \%$ versus $11.0 \%)$, to have multiple birth (6.6\% versus $2.7 \%)$, pregnancy-induced hypertension $(\mathrm{PIH})(17.9 \%$ versus $6.0 \%)$, hypothyroidism (9.3\% versus $3.7 \%)$, preterm birth (17.3\% versus $5.0 \%)$, postpartum hemorrhage 
(14.6\% versus $5.0 \%)$, abruptio placentae (4.0\% versus $1.0 \%)$, ischemic placental diseases $(26.5 \%$ versus $12.0 \%)$, delivery via cesarean delivery ( $81.5 \%$ versus $46.3 \%)$, newborns with low birth weight $(15.2 \%$ versus $4.3 \%)$ and respiratory distress syndrome (6.6\% versus $1.7 \%)$.

\section{Total Weight gain during pregnancy}

In normal-weight women, total GWG was $14.6 \pm 4.7 \mathrm{~kg}$ for $\mathrm{PE}, 12.3 \pm 4.2 \mathrm{~kg}$ for DVT, $13.9 \pm 4.7 \mathrm{~kg}$ for all VTE and $13.2 \pm 4.3 \mathrm{~kg}$ for control (Table S1), and did significantly differ between PE and control group (adjusted estimated mean difference combined $0.06 \mathrm{~kg}, 95 \% \mathrm{Cl} 0.01-0.13 \mathrm{~kg}$ ) (Table 2). A tendency towards decreased risk at lower total weight gain (aOR $0.85 ; 95 \% \mathrm{Cl} 0.43-1.69$ ) and significantly increased risk at higher values ( $\mathrm{aOR}=1.52 ; 95 \% \mathrm{Cl}$ : 1.01-2.31) for $\mathrm{PE}$ was observed in normal-weight women, whereas there was no clear association between total weight gain and DVT or all VTE. As for underweight and overweight women, results from the categorical model for total weight gain indicated an increased risk at both low (aOR 1.85; 95\% $\mathrm{Cl} 0.28-12.08$ and aOR $1.23 ; 95 \% \mathrm{Cl} 0.46-3.27$, respectively) and high weight gain (aOR 2.31; 95\% Cl 0.44-12.16 and aOR 2.13; 95\% Cl 0.67-6.79, respectively), but confidence intervals were wide. In addition, total GWG was not significantly associated with DVT or all VTE (Table 3).

\section{Weight gain during early pregnancy}

The pattern for early pregnancy weight gain showed similar results as those in total pregnancy: In normal-weight women, early GWG was $1.5 \pm 2.7 \mathrm{~kg}$ for PE, $0.7 \pm 1.6 \mathrm{~kg}$ for DVT, $1.3 \pm 2.4 \mathrm{~kg}$ for all VTE and $0.6 \pm 2.3 \mathrm{~kg}$ for control (Table S1), and did significantly differ between PE or all VTE and control group (adjusted estimated mean difference combined $0.03 \mathrm{~kg}, 95 \% \mathrm{Cl} 0-0.10 \mathrm{~kg}, \mathrm{p}=0.0087$ and $0.02 \mathrm{~kg}, 95 \% \mathrm{Cl}$ $0-0.08 \mathrm{~kg}, \mathrm{p}=0.0235$, respectively) (Table 2). There was observed protective effects of low weight gain (aOR $0.79 ; 95 \% \mathrm{Cl} 0.37-1.68)$ and significantly increased risks of high weight gain (aOR=1.47; 95\% $\mathrm{Cl}$ : 1.03-2.09) for $P E$ in normal-weight women. As for underweight women, weight gain above average was associated with an increased risk of $\mathrm{PE}(\mathrm{aOR}=2.50 ; 95 \% \mathrm{Cl}$ : 0.29-21.40), so was for overweight and obese women (aOR=2.13; 95\% Cl: 0.52-8.79), but estimates were not statistically significant. In contrast, associations of weight gain above or below average with DVT or all VTE were not significant, included the null (Table 4).

\section{Weight gain during mid and late pregnancy}

The associations of higher GWG with PE for normal-weight women attenuated towards non-significant in mid and late pregnancy. Similarly, within the range of mid and late weight gain, no significant associations between maternal GWG and increased risk for DVT or all VTE were present, regardless of maternal BMI (Table 5 and 6).

\section{Discussion}

\section{Main Findings}


In this study, we found different associations of gestational stage-specific weight gain with venous thrombosis. Of those, higher GWG in total or early pregnancy was associated with higher risks of PE in normal-weight women. As for underweight and overweight women, results from the categorical model for early or total pregnancy weight gain indicated an increased risk at both low and high weight gain for PE, but confidence intervals were wide.

\section{Strengths and limitations}

There are strengths in our study. Due to the detailed clinical data, such as pre-pregnancy weight, weight measurements at every prenatal visit and weight measurements before delivery beyond the registry, it was possible for us to study both weight gain in different periods of pregnancy and to take the differences in types of VTE (eg, DVT as well as PE) into account. Moreover, use of weight gain z-scores instead of weight gain in kilograms helped to disentangle the effects of pregnancy weight gain on VTE from the effects of gestational duration, because GWG is highly correlated to the gestational duration. Our cohort study extends previous studies by accounting for effect modification by pre-pregnancy BMI and using a gestational age-independent measure of pregnancy weight gain.

There are also limitations in our study. The number of VTE was decreased when stratified by BMIcategories, especially among obese women. For this reason, we analyze the effect of weight gain during pregnancy on VTE in obese together with overweight women. Furthermore, the incidence of VTE might be underestimated in this study, since women who have high risks of VTE during pregnancy typically receive low-molecular-weight heparin (LMWH) and are often not switched to VTE in the postpartum period, which is inevitable.

\section{Interpretation}

GWG has been associated with subsequent risks of adverse pregnancy outcomes, such as preterm birth, pre-eclampsia and caesarean section, has been suggested ${ }^{[18,19]}$, but evidence to clarify the relationship between gestational weight gain and maternal VTE have been sporadic ${ }^{[13,20]}$. A Norwegian hospital-case control study reported that large weight gains ( $>p 90$ or $>21.0 \mathrm{~kg}$ ) were associated with $60 \%$ increased odds of postpartum VTE, while small maternal weight gain is an independent antenatal risk factor for $\mathrm{VTE}^{[13]}$. In a Washington State, USA population-based, case-control study, women with large weight gains during pregnancy $(>22 \mathrm{~kg})$, independently of BMI, were more likely to have VTE $(1.5,95 \% \mathrm{Cl} 1.2-2.1)^{[20]}$. In line with these studies, we observed that higher GWG in whole pregnancy was associated with higher risk of PE. Over weight gain during pregnancy accompanied with increased intraabdominal pressure can encourage blood stasis through iliac vessels compression. Furthermore, elevated inflammatory cytokines and adipokines with increased fat deposition promote endothelial dysfunction and platelet hyperreactivity. Fat deposition also skews the hemostatic-fibrinolytic balance through elevation of procoagulant factors including von Willebrand factor, fibrinogen, factor VII, factor VIII, issue factor, and impairment of fibrinolysis by elevation of plasminogen activator inhibitor ${ }^{[21]}$. On top of differential inflammatory responses, women with high weight have longer durations of labor, greater rates of 
chorioamnionitis, postpartum hemorrhage and surgical complications, which may all lead to the observed greater risk of VTE after delivery ${ }^{[22]}$.

There is growing recognition that the impacts of gestational stage-specific weight gain on pregnancy outcomes may vary ${ }^{[23-27]}$. GWG in early pregnancy largely reflects maternal fat deposition, whereas GWG in mid and late pregnancy is also attributed to maternal and amniotic fluid expansion, and growth of the fetus, placenta and uterus ${ }^{[28]}$. In this study, we found that higher GWG in early pregnancy was associated with higher risks of PE in normal-weight women. As for underweight and overweight women, results from the categorical model for early pregnancy weight gain indicated an increased risk at both low and high weight gain for PE. Studies have found that mothers with increased fat deposition during early pregnancy may involve the multifactorial engagement of alterations to blood flow, hypercoagulability, chronic lowgrade inflammation and endothelial dysfunction, which may lead to $P E^{[21,29]}$. Therefore, GWG in early pregnancy, prior to the development of pregnancy outcomes, might be as or more important than GWG in late pregnancy with respect to pregnancy outcomes.

GWG below average in overweight and obese mothers were also at an increased risk of PE in our analysis. This finding, if true, could result from low amniotic fluid volume and fetal weight by ischemic placental disease (including preeclampsia, intrauterine growth retardation, stillbirth, and placental abruption), perhaps a potential for embolism, leading to $\mathrm{PE}^{[1]}$. Blondon et al found that the delivery of a newborn with low birth weight is associated with a 3-fold increased risk of maternal postpartum VTE ${ }^{[1]}$. In another Norwegian hospital-based, case-control study, mothers of newborns with IUGR were at 3.8-fold risk of postpartum VTE ${ }^{[13]}$. Moreover, hypertension during pregnancy and preeclampsia are also associated with an increased VTE risk during pregnancy and postpartum period ${ }^{[9,30]}$. However, a randomized clinical trial indicated that pre-pregnancy weight loss intervention has favorable effects on the early intrauterine environment ${ }^{[31]}$. Lifestyle intervention during pregnancy could to some extent limit GWG and improve maternal and infant health ${ }^{[32]}$. Therefore, pre-pregnancy weight interventions integrated into intensive weight management that continues through pregnancy may be indispensable to decrease the risks of $\mathrm{PE}$.

There was no statistical association between maternal weight gain and DVT or all VTE across all BMI categories. Similarly, Matthew et al retrospectively analyzed a large database from American found that only the risk of PE is elevated in patient classification as heavier categories after surgery, whereas there was no positive association between DVT and BMI ${ }^{[3,34]}$. Explanations for this observed association exist, of which anticoagulation used for VTE prophylaxis during pregnancy is most plausible. All pregnant women in Shanghai are managed based on RCOG Green-top Guidelines ${ }^{[35]}$ and Quensland Clinical Guidelines ${ }^{[36,37]}$. Briefly, they will undergo a documented assessment of risk factors for VTE throughout pregnancy, intrapartum and the puerperium. Any woman with risk factors shown in Table S2 should be considered for prophylactic low-molecular-weight heparin (LMWH). Previous studies have evaluated the efficacy of LMWH for thromboprophylaxis, revealed that LMWH probably results in little to no difference in the incidence of PE in patients undergoing knee arthroscopy, but reduce the risk of asymptomatic 
$\mathrm{DVT}^{[38]}$. Similarly, eight RCTs showed no clear differences between the LMWH and no prophylaxis or placebo groups in patients with lower-limb immobilization for PE, but less DVT in the LMWH groups ${ }^{[39]}$. Therefore, aggressive pharmacologic anticoagulation regimens during pregnancy can decrease the DVT rate but have not been shown to affect the rate of PE. Meanwhile, common risk factors for DVT, like history of multiple deliveries, smoking, and obesity are less frequently observed in China ${ }^{[15,40]}$. These may be the reasons for the higher incidence of PE in this study. However, the evidence is very uncertain, and further high-quality very large-scale randomized trials are needed to determine effects of currently used treatments in women with different VTE risk factors.

\section{Conclusion}

The GWG associations with venous thrombosis differ at different periods of pregnancy. Of those, maternal weight gain in total or early pregnancy is an important risk factor for PE. In order to effectively improve maternal and child outcomes, pre-pregnancy weight interventions integrated into intensive weight management that continues through pregnancy may be indispensable.

\section{Abbreviations}

VTE: Venous thromboembolism; DVT: Deep venous thrombosis; PE: Pulmonary embolus; GWG: Gestational weight gain; BMI: body mass index; SD: Standard deviations; ART: Assisted reproductive technology; IUI: Intrauterine insemination; IVF: in-vitro fertilization; ICSI: Intracytoplasmic sperm injection; GDM: Gestational diabetes mellitus; PIH: Pregnancy induced hypertension; aORs: Adjusted odds ratios; Cis: Confidence intervals; IUGR: Intrauterine growth retardation; SGA: Small for gestational age; LGA: Large for gestational age; IQR: Interquartile range; SAS: Statistical Analysis System; LMWH: Lowmolecular-weight heparin.

\section{Declarations}

\section{Acknowledgements}

We thank the study participants for permitting us to use their personal data.

\section{Authors' contributions}

YW, JP and LD participated in interpretation of data and involved in drafting the manuscript. $Z Z, T Z, X Z$, $\mathrm{ZH}$ and $\mathrm{RC}$ analyzed the data and critically revised the manuscript. $\mathrm{XH}$ made substantial contributions to conception and design, interpreted the data and critically revised the manuscript. All authors read and approved the final manuscript.

\section{Funding}


This research was supported by the Shanghai Municipal Commission of Health and Family Planning (202040128), and Natural science foundation of Pudong Municipal Health Commission of Shanghai (PW2019D-13).

\section{Availability of data and materials}

The data that support the findings of this study are available from the corresponding author upon reasonable request.

\section{Ethics approval and consent to participate}

This study was approved by Ethics Committee of Shanghai First Maternity and Infant Hospital (reference number: KS2057).

\section{Consent for publication}

Not applicable.

\section{Competing interest}

The authors declare that they have no known competing financial interests or personal relationships that may have influenced the work reported in this paper.

\section{Author details}

${ }^{1}$ Shanghai Key Laboratory of Maternal Fetal Medicine, Shanghai First Maternity and Infant Hospital, School of Medicine, Tongji University, Shanghai, 200092, China. ${ }^{2}$ Obstetrics Department, Shanghai First Maternity and Infant Hospital, School of Medicine, Tongji University, Shanghai, 200092, China

\section{References}

1. Blondon M, Quon BS, Harrington LB, et al. Association between newborn birth weight and the risk of postpartum maternal venous thromboembolism: a population-based case-control study. Circulation. 2015, 131. 17, 1471-1476; discussion 1476.

2. Ghaji N, Boulet SL, Tepper N, et al. Trends in venous thromboembolism among pregnancy-related hospitalizations, United States, 1994-2009. Am J Obstet Gynecol. 2013, 209. 5, 433 e431-438.

3. Nichols KM, Henkin S, Creager MA. Venous Thromboembolism Associated With Pregnancy: JACC Focus Seminar. J Am Coll Cardiol. 2020, 76. 18, 2128-2141.

4. Parunov LA, Soshitova NP, Ovanesov MV, et al. Epidemiology of venous thromboembolism (VTE) associated with pregnancy. Birth Defects Res C Embryo Today. 2015, 105. 3, 167-184.

5. American College of O, Gynecologists' Committee on Practice B-O. ACOG Practice Bulletin No. 196: Thromboembolism in Pregnancy. Obstet Gynecol. 2018, 132. 1, e1-e17. 
6. Abdul Sultan A, Grainge MJ, West J, et al. Impact of risk factors on the timing of first postpartum venous thromboembolism: a population-based cohort study from England. Blood. 2014, 124. 18, 2872-2880.

7. Kim YH, Pfaller B, Marson A, et al. The risk of venous thromboembolism in women with inflammatory bowel disease during pregnancy and the postpartum period: A systematic review and meta-analysis. Medicine (Baltimore). 2019, 98. 38, e17309.

8. Kamel H, Navi BB, Sriram N, et al. Risk of a thrombotic event after the 6-week postpartum period. $N$ Engl J Med. 2014, 370. 14, 1307-1315.

9. Scheres LJJ, Lijfering WM, Groenewegen NFM, et al. Hypertensive Complications of Pregnancy and Risk of Venous Thromboembolism. Hypertension. 2020, 75. 3, 781-787.

10. Sultan AA, West J, Grainge MJ, et al. Development and validation of risk prediction model for venous thromboembolism in postpartum women: multinational cohort study. BMJ. 2016, 355. i6253.

11. Tepper NK, Boulet SL, Whiteman MK, et al. Postpartum venous thromboembolism: incidence and risk factors. Obstet Gynecol. 2014, 123. 5, 987-996.

12. Scheres LJJ, Bistervels IM, Middeldorp S. Everything the clinician needs to know about evidencebased anticoagulation in pregnancy. Blood Rev. 2019, 33. 82-97.

13. Jacobsen AF, Skjeldestad FE, Sandset PM. Ante- and postnatal risk factors of venous thrombosis: a hospital-based case-control study. J Thromb Haemost. 2008, 6. 6, 905-912.

14. Zhu Q, Chen M, Li H. Clinical characteristics and risk factors of pregnancy-related thrombotic diseases. Prog Obstet Gynecol. 2021, Vol. 30षNo. 8.

15. Chen Y, Dai Y, Song J, et al. Establishment of a risk assessment tool for pregnancy-associated venous thromboembolism and its clinical application: protocol for a prospective observational study in Beijing. BMC Pregnancy Childbirth. 2019, 19. 1, 294.

16. Organization WH. Obesity: preventing and managing the global epidemic. Report of a WHO consultation. 2000.

17. Li Z, Rong Z, Zhang S, et al. [Chinese neonatal birth weight curve for different gestational age]. Zhonghua er ke za zhi Chinese journal of pediatrics. 2015, 53. 2, 97-103.

18. Wu Y, Wan S, Gu S, et al. Gestational weight gain and adverse pregnancy outcomes: a prospective cohort study. BMJ Open. 2020, 10. 9, e038187.

19. LifeCycle Project-Maternal O, Childhood Outcomes Study G, Voerman E, et al. Association of Gestational Weight Gain With Adverse Maternal and Infant Outcomes. JAMA. 2019, 321. 17, 17021715.

20. Blondon M, Harrington LB, Boehlen F, et al. Pre-pregnancy BMI, delivery BMI, gestational weight gain and the risk of postpartum venous thrombosis. Thromb Res. 2016, 145. 151-156.

21. Michels A, Dwyer CN, Mewburn J, et al. von Willebrand Factor Is a Critical Mediator of Deep Vein Thrombosis in a Mouse Model of Diet-Induced Obesity. Arterioscler Thromb Vasc Biol. 2020, 40. 12, 2860-2874. 
22. Subramaniam A, Jauk VC, Goss AR, et al. Mode of delivery in women with class III obesity: planned cesarean compared with induction of labor. Am J Obstet Gynecol. 2014, 211. 6, 700 e701-709.

23. Gaillard R, Steegers EA, Franco $\mathrm{OH}$, et al. Maternal weight gain in different periods of pregnancy and childhood cardio-metabolic outcomes. The Generation R Study. Int J Obes (Lond). 2015, 39. 4, 677685 .

24. Fraser A, Tilling K, Macdonald-Wallis C, et al. Association of Maternal Weight Gain in Pregnancy With Offspring Obesity and Metabolic and Vascular Traits in Childhood. Circulation. 2010, 121. 23, 25572564.

25. Laitinen J, Jaaskelainen A, Hartikainen AL, et al. Maternal weight gain during the first half of pregnancy and offspring obesity at 16 years: a prospective cohort study. BJOG. 2012, 119. 6, 716723.

26. Lawlor DA, Paul L, Abigail F, et al. Does maternal weight gain in pregnancy have long-term effects on offspring adiposity? A sibling study in a prospective cohort of 146,894 men from 136,050 families. American Journal of Clinical Nutrition. 2011, 94. 1, 142.

27. Retnakaran R, Wen SW, Tan H, et al. Association of Timing of Weight Gain in Pregnancy With Infant Birth Weight. JAMA Pediatr. 2018, 172. 2, 136-142.

28. Institute of Medicine (US), National Research Council (US) Committee to Reexamine IOM Pregnancy Weight Guidelines. In: Rasmussen KM, Yaktine AL, editors. Weight Gain During Pregnancy. Washington (DC): National Academies Press. 2009.

29. Kopec AK, Abrahams SR, Thornton S, et al. Thrombin promotes diet-induced obesity through fibrindriven inflammation. J Clin Invest. 2017, 127. 8, 3152-3166.

30. van Walraven C, Mamdani M, Cohn A, et al. Risk of subsequent thromboembolism for patients with pre-eclampsia. BMJ. 2003, 326. 7393, 791-792.

31. LeBlanc ES, Smith NX, Vesco KK, et al. Weight loss prior to pregnancy and subsequent gestational weight gain: Prepare, a randomized clinical trial. Am J Obstet Gynecol. 2021, 224. 1, 99 e91-99 e14.

32. Kunath J, Gunther J, Rauh K, et al. Effects of a lifestyle intervention during pregnancy to prevent excessive gestational weight gain in routine care - the cluster-randomised GeliS trial. BMC Med. 2019, 17. 1, 5.

33. Sloan M, Sheth N, Lee GC. Is Obesity Associated With Increased Risk of Deep Vein Thrombosis or Pulmonary Embolism After Hip and Knee Arthroplasty? A Large Database Study. Clin Orthop Relat Res. 2019, 477. 3, 523-532.

34. Mantilla CB, Horlocker TT, Schroeder DR, et al. Risk factors for clinically relevant pulmonary embolism and deep venous thrombosis in patients undergoing primary hip or knee arthroplasty. Anesthesiology. 2003, 99. 3, 552-560; discussion 555A.

35. Gynaecologists RCoO. Reducing the Risk of Venous Thromboembolism during Pregnancy and the Puerperium. Green-top Guideline No. 37a. 2015.

36. Guidelines QC. Guideline supplement: Venous thromboembolism (VTE) in pregnancy and the puerperium. 2020. 
37. Expert consensus on prevention and treatment of obstetric venous thromboembolism in Shanghai. Shanghai Med J. 2020, 43, No.11.

38. Perrotta C, Chahla J, Badariotti G, et al. Interventions for preventing venous thromboembolism in adults undergoing knee arthroscopy. Cochrane Database Syst Rev. 2020, 5. CD 005259.

39. Zee AA, van Lieshout $K$, van der Heide $M$, et al. Low molecular weight heparin for prevention of venous thromboembolism in patients with lower-limb immobilization. Cochrane Database Syst Rev. 2017, 8. CD006681.

40. Gerhardt A, Scharf RE, Greer IA, et al. Hereditary risk factors for thrombophilia and probability of venous thromboembolism during pregnancy and the puerperium. Blood. 2016, 128. 19, 2343-2349.

\section{Tables}

Table 1. Characteristics of cases and controls. 


\begin{tabular}{|c|c|c|c|}
\hline \multirow[t]{2}{*}{ Characteristic } & Controls & Cases & \multirow[t]{2}{*}{$P$ value } \\
\hline & $\square n=302 \square$ & In=1510 & \\
\hline Maternal age(y) & $30.8 \pm 6.0$ & $32.1 \pm 4.3$ & $<0.0001$ \\
\hline Maternal age $\geq 35$ years, $n(\%)$ & $43(14.3)$ & $35(23.2)$ & 0.0184 \\
\hline Nulliparous, n (\%) & $212(70.9)$ & $112(74.2)$ & 0.4658 \\
\hline Education, university degree and above, $\mathrm{n}(\%)$ & $276(91.4)$ & $136(90.1)$ & 0.6728 \\
\hline ART, n (\%) & $36 \rrbracket 12.0 \rrbracket$ & $4 \rrbracket 2.7 \rrbracket$ & 0.0010 \\
\hline Pre-pregnancy BMI $\left(\mathrm{kg} / \mathrm{m}^{2}\right)$, mean $\pm S D$ & $21.6 \pm 2.8$ & $22.0 \pm 3.0$ & 0.3725 \\
\hline \multicolumn{4}{|l|}{ Pre-pregnancy BMI categories, n (\%) } \\
\hline Underweight $(<18.5$ kg/m2) & $31(10.3)$ & $9(6.0)$ & \multirow[t]{3}{*}{0.0074} \\
\hline Normal weight (18.5-24.9 kg/m2) & $237(78.7)$ & $112(74.7)$ & \\
\hline Overweight and obese ( $\geq 25 \mathrm{~kg} / \mathrm{m} 2)$ & $33(11.0)$ & $29(19.3)$ & \\
\hline Gestational age at delivery (week), median (IQR) & $39(38,40)$ & $38(37,39)$ & $<0.0001$ \\
\hline \multicolumn{4}{|l|}{ Mode of delivery } \\
\hline Spontaneous labor & $161 \rrbracket 53.6 \rrbracket$ & $28 \rrbracket 18.5 \rrbracket$ & \multirow[t]{2}{*}{$<0.0001$} \\
\hline Caserean section & $139 \rrbracket 46.3 \rrbracket$ & $123(81.5)$ & \\
\hline Multiple pregnancy & $9 \otimes 2.7 \rrbracket$ & 10冈6.6》 & 0.0284 \\
\hline \multicolumn{4}{|l|}{ Pregnancy complications } \\
\hline GDM & $30 \otimes 10.0 \rrbracket$ & 19ه12.6】 & 0.3993 \\
\hline $\mathrm{PIH}$ & $18 \triangle 6.0 \otimes$ & $27 ه 17.9 \rrbracket$ & $<0.0001$ \\
\hline Hypothyroidism & $11 \otimes 3.7 \rrbracket$ & $14 \otimes 9.3 \rrbracket$ & 0.0138 \\
\hline Preterm birth & $15(5.0)$ & $26(17.3)$ & $<0.0001$ \\
\hline Postpartum hemorrhage & $15 \rrbracket 5.0 \bigotimes$ & $22 \bigotimes 14.6 \rrbracket$ & 0.0005 \\
\hline Ischemic placental diseases & $36 \rrbracket 12.0 \rrbracket$ & $40 \rrbracket 26.5 \rrbracket$ & $<0.0001$ \\
\hline Premature rupture of membranes & $55(18.3)$ & $31(20.5)$ & 0.5646 \\
\hline Placenta previa & $3(1.0)$ & $4(2.7)$ & 0.1801 \\
\hline Abruptio placentae & $3(1.0)$ & $6(4.0)$ & 0.0328 \\
\hline Postpartum transfusion & $6 \rrbracket 2.0 \rrbracket$ & $5 \rrbracket 3.3 \rrbracket$ & 0.3916 \\
\hline Infant Gender (female) & $153(50.8)$ & $87(57.6)$ & 0.1732 \\
\hline
\end{tabular}




\begin{tabular}{|c|c|c|c|}
\hline Birth Weight (gm) (Mean \pm SD) & $3246 \pm 449$ & $3168 \pm 663$ & $<0.0001$ \\
\hline$S G A \leq 10^{\text {th }}$ & $19 \llbracket 6.3 \rrbracket$ & 10冈6.6》 & 0.8991 \\
\hline$L G A \geq 90^{\text {th }}$ & 17ه5.7凶 & 16ه10.6ه & 0.0568 \\
\hline Macrosomia (>4000 g) & 11区3.7区 & $8 \otimes 5.3 \rrbracket$ & 0.4120 \\
\hline Low birthweight (<2500 g) & $13 \rrbracket 4.3 \rrbracket$ & $23 \rrbracket 15.2 \rrbracket$ & $<0.0001$ \\
\hline Very low birthweight $(<2500 \mathrm{~g})$ & $2 \otimes 0.7 \rrbracket$ & $4 \rrbracket 3.3 \rrbracket$ & 0.0824 \\
\hline Sentinel congenital anomalies & $7 \rrbracket 2.3 \rrbracket$ & $6 \varangle 4.0 \rrbracket$ & 0.3233 \\
\hline Hyperbilirubinemia & $32 \bigotimes 10.6 \rrbracket$ & $24 \rrbracket 15.9 \rrbracket$ & 0.1096 \\
\hline Respiratory distress syndrome & $5 \bigotimes 1.7 \rrbracket$ & 10囚6.6囚 & 0.0055 \\
\hline
\end{tabular}

Abbreviations: BMI: body mass index; GDM: gestational diabetes mellitus; PIH: pregnancy induced hypertension; SGA: small for gestational age; LGA: large for gestational age; IQR: median with interquartile range.

Table 2. Absolute effect size of gestational weight gain at different periods of pregnancy. 


\begin{tabular}{|c|c|c|c|c|c|c|}
\hline & $\begin{array}{l}\text { PE } \\
\text { Adjusted } \\
\text { effect size } \\
(95 \% \mathrm{Cl}) \\
(\mathrm{n}=99)\end{array}$ & $P$ value & $\begin{array}{l}\text { DVT with PE } \\
\text { or without PE } \\
\text { Adjusted } \\
\text { effect size } \\
(95 \% \mathrm{Cl}) \\
(\mathrm{n}=52)\end{array}$ & $P$ value & $\begin{array}{l}\text { All VTE } \\
\begin{array}{l}\text { Adjusted } \\
\text { effect size } \\
(95 \% \mathrm{Cl}) \\
(\mathrm{n}=151)\end{array}\end{array}$ & $P$ value \\
\hline \multicolumn{7}{|c|}{ Total GWG in pregnancy by BMI categories } \\
\hline $\begin{array}{l}\text { Underweight (< } \\
18.5 \mathrm{~kg} / \mathrm{m} 2)\end{array}$ & $-0.04(0,0.26)$ & 0.2645 & $\begin{array}{l}0.31(0, \\
0.57)^{*}\end{array}$ & 0.0063 & $\begin{array}{l}0.03(0 \\
0.31)\end{array}$ & 0.0516 \\
\hline $\begin{array}{l}\text { Normal weight } \\
(18.5-24.9 \mathrm{~kg} / \mathrm{m} 2)\end{array}$ & $\begin{array}{l}0.06(0.01 \\
0.13)^{*}\end{array}$ & 0.0149 & $\begin{array}{l}0.05(0.01 \\
0.12)\end{array}$ & 0.2752 & $\begin{array}{l}0.05(0.01 \\
0.11)\end{array}$ & 0.1191 \\
\hline $\begin{array}{l}\text { Overweight and } \\
\text { obese }(\geq 25 \\
\mathrm{kg} / \mathrm{m} 2)\end{array}$ & $0.06(0,0.31)$ & 0.7018 & $0.02(0,0.27)$ & 0.4258 & $\begin{array}{l}0.07(0, \\
0.27)\end{array}$ & 0.6870 \\
\hline \multicolumn{7}{|c|}{ GWG in early pregnancy by BMI categories } \\
\hline $\begin{array}{l}\text { Underweight }< \\
18.5 \mathrm{~kg} / \mathrm{m} 2)\end{array}$ & $0.30(0,0.59)$ & 0.0542 & $0.33(0,0.63)$ & 0.0596 & $\begin{array}{l}0.29(0 \\
0.59)\end{array}$ & 0.0542 \\
\hline $\begin{array}{l}\text { Normal weight } \\
(18.5-24.9 \mathrm{~kg} / \mathrm{m} 2)\end{array}$ & $0.03(0,0.10)$ * & 0.0087 & $-0.01(0,0.04)$ & 0.7320 & $\begin{array}{l}0.02(0, \\
0.08)^{*}\end{array}$ & 0.0235 \\
\hline $\begin{array}{l}\text { Overweight and } \\
\text { obese }(\geq 25 \\
\mathrm{kg} / \mathrm{m} 2)\end{array}$ & $-0.05(0,0.27)$ & 0.4264 & $-0.08(0,0.24)$ & 0.1886 & $\begin{array}{l}0.01(0 \\
0.26)\end{array}$ & 0.1424 \\
\hline \multicolumn{7}{|c|}{ GWG in mid pregnancy by BMI categories } \\
\hline $\begin{array}{l}\text { Underweight (< } \\
18.5 \mathrm{~kg} / \mathrm{m} 2)\end{array}$ & $0.09(0,0.46)$ & 0.3084 & $0.01(0,0.41)$ & 0.0797 & $\begin{array}{l}0.14(0, \\
0.50)^{*}\end{array}$ & 0.0065 \\
\hline $\begin{array}{l}\text { Normal weight } \\
(18.5-24.9 \mathrm{~kg} / \mathrm{m} 2)\end{array}$ & $0.00(0,0.06)$ & 0.4225 & $0.00(0,0.07)$ & 0.3731 & $\begin{array}{l}0.01(0 \\
0.07)\end{array}$ & 02473 \\
\hline $\begin{array}{l}\text { Overweight and } \\
\text { obese }(\geq 25 \\
\mathrm{kg} / \mathrm{m} 2)\end{array}$ & $0.15(0,0.44)$ & 0.1499 & $-0.02(0,0.31)$ & 0.5082 & $\begin{array}{l}0.11(0 \\
0.37)\end{array}$ & 0.1470 \\
\hline \multicolumn{7}{|c|}{ GWG in late pregnancy by BMI categories } \\
\hline $\begin{array}{l}\text { Underweight }(< \\
18.5 \mathrm{~kg} / \mathrm{m} 2)\end{array}$ & $-0.06(0,0.23)$ & 0.3860 & $-0.02(0,0.31)$ & 0.1161 & $\begin{array}{l}-0.07(0, \\
0.21)\end{array}$ & 0.6476 \\
\hline $\begin{array}{l}\text { Normal weight } \\
(18.5-24.9 \mathrm{~kg} / \mathrm{m} 2)\end{array}$ & $0.03(0,0.09)$ & 0.1246 & $\begin{array}{l}0.05(0.01 \\
0.12)^{*}\end{array}$ & 0.0295 & $\begin{array}{l}0.03(0 \\
0.08)\end{array}$ & 0.8666 \\
\hline $\begin{array}{l}\text { Overweight and } \\
\text { obese }(\geq 25 \\
\mathrm{kg} / \mathrm{m} 2)\end{array}$ & $-0.04(0,0.21)$ & 0.4134 & $0.05(0,0.31)$ & 0.0541 & $\begin{array}{l}0.01(0 \\
0.22)\end{array}$ & 0.1369 \\
\hline
\end{tabular}


Abbreviations: BMI: body mass index; DVT: deep venous thrombosis; PE: pulmonary embolus; VTE: venous thromboembolism.

Table 3. Maternal total pregnancy weight gain by z-score categories with adjusted odds ratios for PE alone, DVT (including DVT and concomitant PE) and all VTE events.

\begin{tabular}{|c|c|c|c|c|c|c|c|c|}
\hline \multirow[t]{2}{*}{$\begin{array}{l}\text { BMI } \\
\text { category }\end{array}$} & $\begin{array}{l}\text { Total } \\
\text { Weight } \\
\text { Gain }\end{array}$ & \multirow[t]{2}{*}{ Control } & \multirow[t]{2}{*}{ PE } & \multirow[t]{2}{*}{$\begin{array}{l}\text { Adjusted } \\
\text { odds ratio } \\
(95 \% \mathrm{Cl})\end{array}$} & \multirow{2}{*}{$\begin{array}{l}\text { DVT } \\
\text { with PE } \\
\text { or } \\
\text { without } \\
\text { PE }\end{array}$} & \multirow{2}{*}{$\begin{array}{l}\text { Adjusted } \\
\text { odds } \\
\text { ratio } \\
(95 \% \mathrm{Cl})\end{array}$} & \multirow[t]{2}{*}{$\begin{array}{l}\text { All } \\
\text { VTE }\end{array}$} & \multirow{2}{*}{$\begin{array}{l}\text { Adjusted } \\
\text { odds } \\
\text { ratio } \\
(95 \% \mathrm{Cl})\end{array}$} \\
\hline & $\begin{array}{l}\text { z-score } \\
\text { category }\end{array}$ & & & & & & & \\
\hline \multirow[t]{3}{*}{$\begin{array}{l}\text { Underweight } \\
(<18.5 \\
\mathrm{kg} / \mathrm{m} 2)\end{array}$} & $\nabla-1$ & 4 & 1 & $\begin{array}{l}1.85(0.28 \\
12.08)\end{array}$ & 0 & NA & 1 & $\begin{array}{l}0.87 \\
(0.55 \\
1.38)\end{array}$ \\
\hline & -1 to 1 & 23 & 3 & Ref & 0 & Ref & 3 & Ref \\
\hline & $\nabla 1$ & 4 & 2 & $\begin{array}{l}2.31(0.44, \\
12.16)\end{array}$ & 2 & NA & 4 & $\begin{array}{l}0.66 \\
(0.33 \\
1.30)\end{array}$ \\
\hline \multirow[t]{3}{*}{$\begin{array}{l}\text { Normal } \\
\text { weight (18.5- } \\
24.9) \mathrm{kg} / \mathrm{m} 2\end{array}$} & $\bigotimes-1$ & 28 & 7 & $\begin{array}{l}0.85(0.43, \\
1.69)\end{array}$ & 9 & $\begin{array}{l}1.77 \\
(0.92 \\
3.41)\end{array}$ & 16 & $\begin{array}{l}1.00 \\
(0.89 \\
1.13)\end{array}$ \\
\hline & -1 to 1 & 171 & 48 & Ref & 20 & Ref & 68 & Ref \\
\hline & $\nabla 1$ & 34 & 19 & $\begin{array}{l}1.52(1.01 \\
2.31)^{*}\end{array}$ & 4 & $\begin{array}{l}0.81 \\
(0.30 \\
2.16)\end{array}$ & 23 & $\begin{array}{l}0.97 \\
(0.87 \\
1.09)^{\prime}\end{array}$ \\
\hline \multirow{3}{*}{$\begin{array}{l}\text { Overweight } \\
\text { and obese } \\
(\geq 25 \mathrm{~kg} / \mathrm{m} 2)\end{array}$} & $\bigotimes-1$ & 7 & 3 & $\begin{array}{l}1.23(0.46 \\
3.27)\end{array}$ & 3 & $\begin{array}{l}1.09 \\
(0.44, \\
2.68)\end{array}$ & 6 & $\begin{array}{l}0.98 \\
(0.70 \\
1.37)\end{array}$ \\
\hline & -1 to 1 & 22 & 8 & Ref & 9 & Ref & 17 & Ref \\
\hline & $\nabla 1$ & 4 & 4 & $\begin{array}{l}2.13 \\
(0.67,6.79)\end{array}$ & 1 & $\begin{array}{l}0.67 \\
(0.10 \\
4.43)\end{array}$ & 5 & $\begin{array}{l}0.95 \\
(0.70 \\
1.29)\end{array}$ \\
\hline
\end{tabular}

Adjusted maternal age, parity, ART, delivery mode, fetal number, birthweight, gestational age, PIH, GDM and postpartum hemorrhage.

Abbreviations: BMI: body mass index; DVT: deep venous thrombosis; PE: pulmonary embolus; VTE: venous thromboembolism.

Table 4. Maternal early pregnancy weight gain by z-score categories with adjusted odds ratios for PE alone, DVT (including DVT and concomitant PE) and all VTE events. 


\begin{tabular}{|c|c|c|c|c|c|c|c|c|}
\hline \multirow[t]{3}{*}{$\begin{array}{l}\text { BMI } \\
\text { category }\end{array}$} & $\begin{array}{l}\text { Early } \\
\text { Weight } \\
\text { Gain }\end{array}$ & \multirow[t]{3}{*}{ Control } & \multirow[t]{3}{*}{ PE } & $\begin{array}{l}\text { Adjusted } \\
\text { odds } \\
\text { ratio }\end{array}$ & \multirow[t]{3}{*}{$\begin{array}{l}\text { DVT with } \\
\text { PE or } \\
\text { without PE }\end{array}$} & \multirow{3}{*}{$\begin{array}{l}\text { Adjusted } \\
\text { odds } \\
\text { ratio } \\
(95 \% \mathrm{Cl})\end{array}$} & \multirow[t]{3}{*}{$\begin{array}{l}\text { All } \\
\text { VTE }\end{array}$} & \multirow{3}{*}{$\begin{array}{l}\text { Adjusted } \\
\text { odds } \\
\text { ratio } \\
(95 \% \mathrm{Cl})\end{array}$} \\
\hline & z-score & & & $(95 \% \mathrm{Cl})$ & & & & \\
\hline & category & & & & & & & \\
\hline \multirow{3}{*}{$\begin{array}{l}\text { Underweight } \\
(<18.5 \\
\mathrm{kg} / \mathrm{m} 2)\end{array}$} & $\mathbb{Q}-1$ & 2 & 0 & NA & 0 & NA & 0 & NA \\
\hline & -1 to 1 & 18 & 2 & Ref & 1 & Ref & 3 & Ref \\
\hline & $\unrhd 1$ & 3 & 1 & $\begin{array}{l}2.50 \\
(0.29 \\
21.40)\end{array}$ & 0 & NA & 1 & $\begin{array}{l}0.87 \\
(0.43 \\
1.74)\end{array}$ \\
\hline \multirow{3}{*}{$\begin{array}{l}\text { Normal } \\
\text { weight } \\
(18.5-24.9 \\
\mathrm{kg} / \mathrm{m} 2)\end{array}$} & $\mathbb{Q}-1$ & 19 & 4 & $\begin{array}{l}0.79 \\
(0.37 \\
1.68)\end{array}$ & 2 & $\begin{array}{l}0.80 \\
(0.21 \\
3.01)^{\prime}\end{array}$ & 6 & $\begin{array}{l}1.02 \\
(0.85, \\
1.22)\end{array}$ \\
\hline & -1 to 1 & 145 & 46 & Ref & 23 & Ref & 69 & Ref \\
\hline & $\nabla 1$ & 23 & 15 & $\begin{array}{l}1.47 \\
(1.03 \\
2.09)^{*}\end{array}$ & 1 & $\begin{array}{l}0.41 \\
(0.06 \\
2.91)\end{array}$ & 16 & $\begin{array}{l}0.98 \\
(0.85, \\
1.12)\end{array}$ \\
\hline \multirow{3}{*}{$\begin{array}{l}\text { Overweight } \\
\text { and obese } \\
(\geq 25 \mathrm{~kg} / \mathrm{m} 2)\end{array}$} & $\mathbb{Q}-1$ & 2 & 0 & NA & 0 & NA & 0 & NA \\
\hline & -1 to 1 & 21 & 9 & Ref & 7 & Ref & 16 & Ref \\
\hline & $\otimes 1$ & 1 & 2 & $\begin{array}{l}2.13 \\
(0.52, \\
8.79)\end{array}$ & 3 & $\begin{array}{l}1.46 \\
(0.46, \\
4.67)\end{array}$ & 5 & $\begin{array}{l}0.78 \\
(0.47 \\
1.30)^{\prime}\end{array}$ \\
\hline
\end{tabular}

*Adjusted maternal age, parity, ART, delivery mode, fetal number, birthweight, gestational age, PIH, GDM and postpartum hemorrhage.

Abbreviations: BMI: body mass index; DVT: deep venous thrombosis; PE: pulmonary embolus; VTE: venous thromboembolism.

Table 5. Maternal mid pregnancy weight gain by z-score categories with adjusted odds ratios for PE alone, DVT (including DVT and concomitant PE) and all VTE events. 


\begin{tabular}{|c|c|c|c|c|c|c|c|c|}
\hline \multirow[t]{3}{*}{$\begin{array}{l}\text { BMI } \\
\text { category }\end{array}$} & $\begin{array}{l}\text { Mid } \\
\text { Weight } \\
\text { Gain }\end{array}$ & \multirow[t]{3}{*}{ Control } & \multirow[t]{3}{*}{$\mathrm{PE}$} & \multirow{3}{*}{$\begin{array}{l}\text { Adjusted } \\
\text { odds } \\
\text { ratio } \\
(95 \% \mathrm{Cl})\end{array}$} & \multirow{3}{*}{$\begin{array}{l}\text { DVT with } \\
\text { PE or } \\
\text { without } \\
\text { PE }\end{array}$} & \multirow{3}{*}{$\begin{array}{l}\text { Adjusted } \\
\text { odds } \\
\text { ratio } \\
(95 \% \mathrm{Cl})\end{array}$} & \multirow[t]{3}{*}{$\begin{array}{l}\text { All } \\
\text { VTE }\end{array}$} & \multirow{3}{*}{$\begin{array}{l}\text { Adjusted } \\
\text { odds } \\
\text { ratio } \\
(95 \% \mathrm{Cl})\end{array}$} \\
\hline & z-score & & & & & & & \\
\hline & category & & & & & & & \\
\hline \multirow{3}{*}{$\begin{array}{l}\text { Underweight (< } \\
18.5 \mathrm{~kg} / \mathrm{m} 2)\end{array}$} & $\mathbb{Q}-1$ & 3 & 0 & NA & 0 & NA & 0 & NA \\
\hline & -1 to 1 & 17 & 0 & Ref & 0 & Ref & 0 & Ref \\
\hline & $\nabla 1$ & 3 & 2 & NA & 1 & NA & 3 & NA \\
\hline \multirow[t]{3}{*}{$\begin{array}{l}\text { Normal weight } \\
(18.5-24.9) \\
\mathrm{kg} / \mathrm{m} 2\end{array}$} & $\mathbb{Q}-1$ & 23 & 6 & $\begin{array}{l}1.29 \\
(0.84 \\
1.98)\end{array}$ & 3 & $\begin{array}{l}0.96 \\
(0.31 \\
3.00)\end{array}$ & 9 & $\begin{array}{l}1.00 \\
(0.88 \\
1.14)\end{array}$ \\
\hline & -1 to 1 & 128 & 46 & Ref & 19 & Ref & 65 & Ref \\
\hline & $\otimes 1$ & 36 & 10 & $\begin{array}{l}0.96 \\
(0.56 \\
1.65)\end{array}$ & 2 & $\begin{array}{l}0.44 \\
(0.11 \\
1.81)\end{array}$ & 12 & $\begin{array}{l}1.02 \\
(0.90 \\
1.16)\end{array}$ \\
\hline \multirow{3}{*}{$\begin{array}{l}\text { Overweight and } \\
\text { obese } \\
(\geq 25 \mathrm{~kg} / \mathrm{m} 2)\end{array}$} & Q-1 & 4 & 1 & $\begin{array}{l}0.78 \\
(0.30 \\
3.02)\end{array}$ & 1 & $\begin{array}{l}0.88 \\
(0.16 \\
4.75)\end{array}$ & 2 & $\begin{array}{l}1.08 \\
(0.71 \\
1.63)\end{array}$ \\
\hline & -1 to 1 & 16 & 8 & Ref & 8 & Ref & 16 & Ref \\
\hline & $\otimes 1$ & 4 & 2 & $\begin{array}{l}1.44 \\
(0.40 \\
5.25)\end{array}$ & 0 & NA & 2 & $\begin{array}{l}1.07 \\
(0.70 \\
1.63)\end{array}$ \\
\hline
\end{tabular}

Adjusted maternal age, parity, ART, delivery mode, fetal number, birthweight, gestational age, PIH, GDM and postpartum hemorrhage.

Abbreviations: BMI: body mass index; DVT: deep venous thrombosis; PE: pulmonary embolus; VTE: venous thromboembolism.

Table 6. Maternal late pregnancy weight gain by z-score categories with adjusted odds ratios for PE alone, DVT (including DVT and concomitant PE) and all VTE events. 


\begin{tabular}{|c|c|c|c|c|c|c|c|c|}
\hline \multirow[t]{3}{*}{$\begin{array}{l}\text { BMI } \\
\text { category }\end{array}$} & $\begin{array}{l}\text { Late } \\
\text { Weight } \\
\text { Gain }\end{array}$ & \multirow[t]{3}{*}{ Control } & \multirow[t]{3}{*}{ PE } & \multirow{3}{*}{$\begin{array}{l}\text { Adjusted } \\
\text { odds } \\
\text { ratio } \\
(95 \% \mathrm{Cl})\end{array}$} & \multirow[t]{3}{*}{$\begin{array}{l}\text { DVT with } \\
\text { PE or } \\
\text { without } \\
\text { PE }\end{array}$} & $\begin{array}{l}\text { Adjusted } \\
\text { odds } \\
\text { ratio }\end{array}$ & \multirow[t]{3}{*}{$\begin{array}{l}\text { All } \\
\text { VTE }\end{array}$} & \multirow{3}{*}{$\begin{array}{l}\text { Adjusted } \\
\text { odds } \\
\text { ratio } \\
(95 \% \mathrm{Cl})\end{array}$} \\
\hline & z-score & & & & & $(95 \% \mathrm{Cl})$ & & \\
\hline & category & & & & & & & \\
\hline \multirow[t]{3}{*}{$\begin{array}{l}\text { Underweight (< } \\
18.5 \mathrm{~kg} / \mathrm{m} 2)\end{array}$} & $\bigotimes-1$ & 6 & 1 & $\begin{array}{l}4.25 \\
(0.83 \\
21.68)\end{array}$ & 0 & NA & 1 & $\begin{array}{l}0.83 \\
(0.54 \\
1.28)\end{array}$ \\
\hline & -1 to 1 & 19 & 2 & Ref & 1 & Ref & 3 & Ref \\
\hline & $\nabla 1$ & 6 & 1 & $\begin{array}{l}2.13 \\
(0.25 \\
18.05)\end{array}$ & 1 & $\begin{array}{l}2.86 \\
(0.20 \\
39.83)\end{array}$ & 2 & $\begin{array}{l}0.93 \\
(0.64 \\
1.35)\end{array}$ \\
\hline \multirow[t]{3}{*}{$\begin{array}{l}\text { Normal weight } \\
(18.5-24.9 \\
\mathrm{kg} / \mathrm{m} 2)\end{array}$} & $\bigotimes-1$ & 37 & 9 & $\begin{array}{l}0.86 \\
(0.54 \\
1.35)\end{array}$ & 8 & $\begin{array}{l}1.64 \\
(0.78 \\
3.45)\end{array}$ & 17 & $\begin{array}{l}1.01 \\
(0.90 \\
1.14)\end{array}$ \\
\hline & -1 to 1 & 165 & 48 & Ref & 21 & Ref & 69 & Ref \\
\hline & $\unrhd 1$ & 32 & 13 & $\begin{array}{l}1.01 \\
(0.67 \\
1.52)\end{array}$ & 4 & $\begin{array}{l}1.03 \\
(0.38 \\
2.80)\end{array}$ & 17 & $\begin{array}{l}0.99 \\
(0.87 \\
1.12)\end{array}$ \\
\hline \multirow{3}{*}{$\begin{array}{l}\text { Overweight } \\
\text { and obese } \\
(\geq 25 \mathrm{~kg} / \mathrm{m} 2)\end{array}$} & $\bigotimes-1$ & 2 & 3 & $\begin{array}{l}2.84 \\
(0.57 \\
14.13)\end{array}$ & 2 & $\begin{array}{l}1.01 \\
(0.35 \\
2.93)\end{array}$ & 5 & $\begin{array}{l}0.79 \\
(0.43 \\
1.44)\end{array}$ \\
\hline & -1 to 1 & 24 & 8 & Ref & 10 & Ref & 18 & Ref \\
\hline & $\nabla 1$ & 6 & 2 & $\begin{array}{l}1.19 \\
(0.36 \\
3.94)\end{array}$ & 0 & NA & 2 & $\begin{array}{l}1.19 \\
(0.65 \\
2.18)\end{array}$ \\
\hline
\end{tabular}

Adjusted maternal age, parity, ART, delivery mode, fetal number, birthweight, gestational age, PIH, GDM and postpartum hemorrhage.

Abbreviations: BMI: body mass index; DVT: deep venous thrombosis; PE: pulmonary embolus; VTE: venous thromboembolism.

\section{Figures}


Women who gave birth between January 1st, 2017 to July 31th, 2021 in Shanghai First Maternity and Infant Hospital

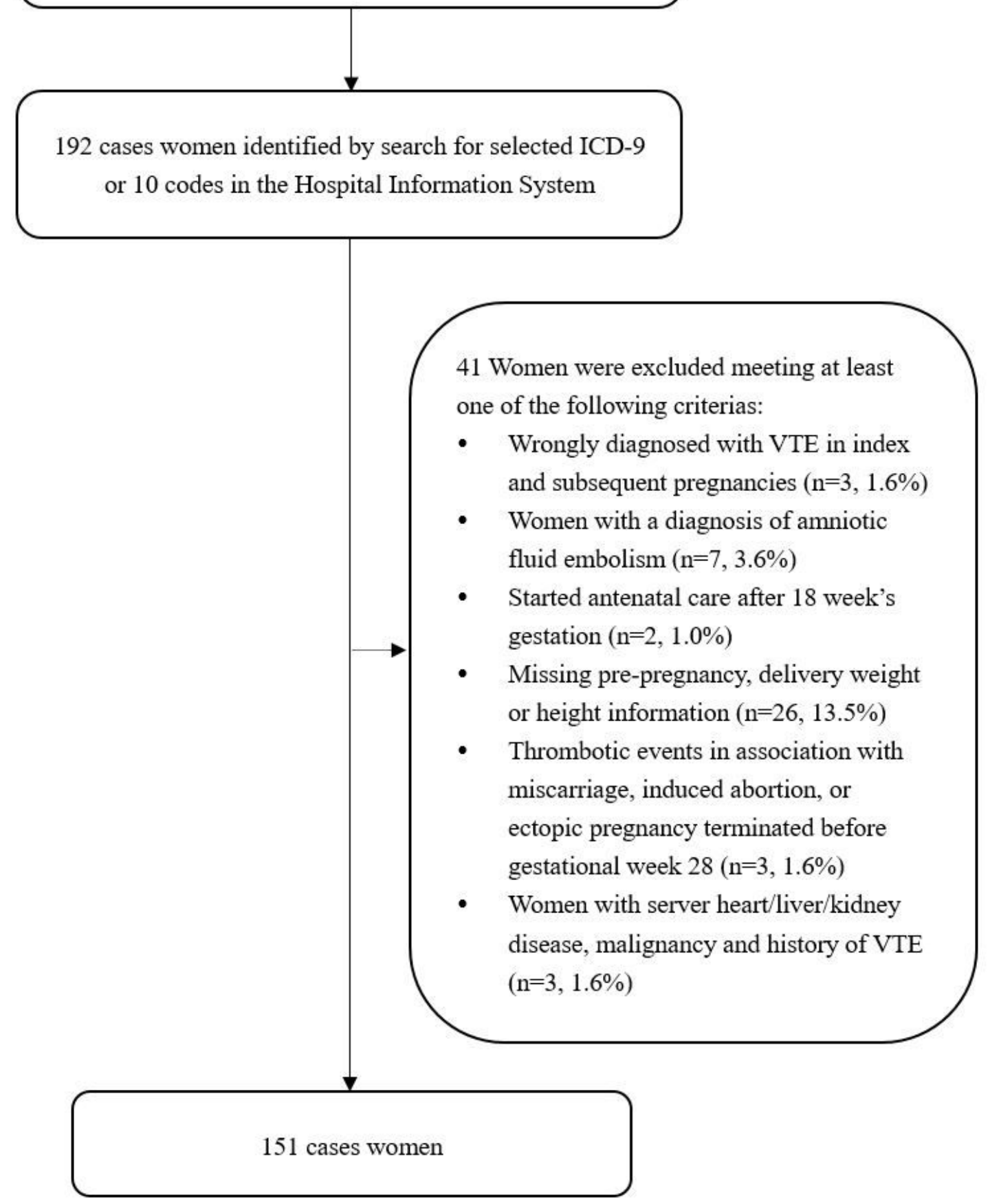

\section{Figure 1}

Study flow chart.

\section{Supplementary Files}

This is a list of supplementary files associated with this preprint. Click to download. 
- TableS09.30.docx

Page 22/22 